\title{
Association between fatality rate of COVID- 19 and selenium deficiency in China
}

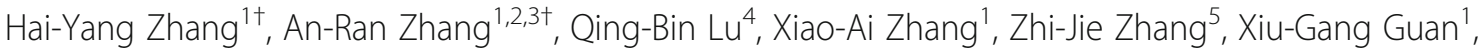 \\ Tian-Le Che ${ }^{1}$, Yang Yang ${ }^{3}$, Hao Li ${ }^{1 *}$, Wei Liu ${ }^{1,4^{*}}$ and Li-Qun Fang ${ }^{1 *}$
}

\begin{abstract}
Background: COVID-19 has impacted populations around the world, with the fatality rate varying dramatically across countries. Selenium, as one of the important micronutrients implicated in viral infections, was suggested to play roles.

Methods: An ecological study was performed to assess the association between the COVID-19 related fatality and the selenium content both from crops and topsoil, in China.

Results: Totally, 14,045 COVID-19 cases were reported from 147 cities during 8 December 2019-13 December 2020 were included. Based on selenium content in crops, the case fatality rates (CFRs) gradually increased from 1.17\% in non-selenium-deficient areas, to $1.28 \%$ in moderate-selenium-deficient areas, and further to $3.16 \%$ in severeselenium-deficient areas $(P=0.002)$. Based on selenium content in topsoil, the CFRs gradually increased from $0.76 \%$ in non-selenium-deficient areas, to $1.70 \%$ in moderate-selenium-deficient areas, and further to $1.85 \%$ in severeselenium-deficient areas $(P<0.001)$. The zero-inflated negative binomial regression model showed a significantly higher fatality risk in cities with severe-selenium-deficient selenium content in crops than non-selenium-deficient cities, with incidence rate ratio (IRR) of 3.88 (95\% Cls: 1.21-12.52), which was further confirmed by regression fitting the association between CFR of COVID-19 and selenium content in topsoil, with the IRR of 2.38 (95\% Cls: 1.14-4.98) for moderate-selenium-deficient cities and 3.06 (1.49-6.27) for severe-selenium-deficient cities.
\end{abstract}

Conclusions: Regional selenium deficiency might be related to an increased CFR of COVID-19. Future studies are needed to explore the associations between selenium status and disease outcome at individual-level.

Keywords: COVID-19, Case fatality rate, Selenium, Micronutrient, China

\section{Background}

The recent outbreak of coronavirus disease 2019 (COVID-19) caused by severe acute respiratory syndrome coronavirus 2 (SARS-CoV-2) has turned the world into chaos with its ominously high rate of transmissions. To the end of 2020, the pandemic has resulted in more than $1,618,374$ deaths, however, with the case

\footnotetext{
*Correspondence: lihao_1986@126.com; liuwei@bmi.ac.cn; fang_lq@163.com ${ }^{+}$Hai-Yang Zhang and An-Ran Zhang contributed equally to this work. ${ }^{1}$ State Key Laboratory of Pathogen and Biosecurity, Beijing Institute of Microbiology and Epidemiology, 20 Dong-Da Street, Fengtai District, Beijing 100071, People's Republic of China

Full list of author information is available at the end of the article
}

fatality rate (CFR) varying dramatically across countries [1]. Currently, there is no specific treatment with proven therapy for COVID-19, especially for those with severe disease. Although some clinical studies have provided a reference for treating of patients, which helps some patients recover quickly, such as remdesivir [2], the efficacy of these drugs remained highly controversial. The factors that might contribute to the disease outcome had been intensively explored, which included age, gender, underlying conditions and others. For these known factors, the functional mechanisms underlying their role in clinical

(c) The Author(s). 2021 Open Access This article is licensed under a Creative Commons Attribution 4.0 International License, which permits use, sharing, adaptation, distribution and reproduction in any medium or format, as long as you give appropriate credit to the original author(s) and the source, provide a link to the Creative Commons licence, and indicate if changes were made. The images or other third party material in this article are included in the article's Creative Commons licence, unless indicated otherwise in a credit line to the material. If material is not included in the article's Creative Commons licence and your intended use is not permitted by statutory regulation or exceeds the permitted use, you will need to obtain permission directly from the copyright holder. To view a copy of this licence, visit http://creativecommons.org/licenses/by/4.0/ The Creative Commons Public Domain Dedication waiver (http://creativecommons.org/publicdomain/zero/1.0/) applies to the data made available in this article, unless otherwise stated in a credit line to the data. 
phenotype was suggested to be orchestrated by the host immune response.

Immune support by micronutrients, including vitamins A, D, C, E, B6, and B12, folate, zinc, iron, copper, and selenium, had long been established to play pivotal role in the defense against infectious diseases [3, 4]. Among all the micronutrients implicated in viral infection, selenium is of high importance for human health and particularly for a well-balanced immune response, mostly through its function in antioxidant defense, redox signaling, and redox homeostasis [5-8]. As demonstrated in previous studies, its deficiency has been related to higher susceptibility to RNA viral infections and more severe disease outcome $[6,9,10]$. Selenium status not only affect the host immune response but also alter the viral pathogen itself $[6,11,12]$. The deficiency of selenium leads to oxidative stress in the host, thus alter the genome of RNA viruses in the way that a normally benign or mildly pathogenic virus becomes highly virulent in the selenium deficient and oxidatively stressed host, for instance, human immunodeficiency virus (HIV), coxsackie virus, and influenza virus $[7,11,13,14]$. The differences in the baseline immune capabilities due to intake of selenium might influence the occurrence and outcome of multiple viral infectious diseases $[5,6,15$, 16], although observational studies associations between selenium intake and these diseases have been inconsistently shown in several studies $[17,18]$. Based on these previous knowledges, it is justified to hypothesize that the selenium status might as well impact the infection of SARS-CoV-2.

The intake of selenium varies worldwide, and China is known to be one of the most severely selenium deficient countries in the world, with a wide range of selenium level that differs from the lowest to the highest in the world. Considering that fatality rate of COVID-19 also varied across different afflicted regions in China [19], we wondered if there might be a relationship between disease severity of COVID-19 and selenium level [20]. Here we applied an ecological study to evaluate the association between COVID-19 related fatality and the selenium content in crops and topsoil at the population level in China.

\section{Materials and methods}

Data collection on COVID-19 patients and selenium level

The data on confirmed COVID-19 cases and deceased cases at the city level in the mainland of China reported during 8 December 2019-13 December 2020 were obtained from the DXY website, a nongovernment website that provided daily updates of the reports from official sources, mainly involving websites of the health commissions of each province, municipality, or city [21]. The CFRs at the city level were calculated by dividing the observed number of deaths by the number of confirmed cases. As we know, Hubei Province, as the first epicenter of COVID-19 outbreak, suffered a great chaos and shortage of medical and health source at the early stages of the first wave of COVID-19 epidemic, which has not occurred in any other provinces in China. The crude case fatality rate in Hubei Province were 7.3 times of that in the combination of all other provinces at the first wave of the epidemic [22]. Hubei Province was excluded from the current analysis to avoid biasing the association between fatality rate of COVID-19 and selenium deficiency due to the influence of the shortage of medical and health source in Hubei Province. Cities that reported less than 20 cases were also excluded to avoid the bias from small sample size. Cases imported from abroad were excluded from the analysis because their clinical phenotype was largely not influenced by the selenium content in China.

This study was approved by the institutional review board of the Beijing Institute of Microbiology and Epidemiology (Beijing, China). All data were collected from publicly available sources. Data were de-identified, and informed consent was waived.

Data on social-demographic co-variables, possibly related to the mortality of COVID-19 mortality, including population density, proportion of population over 60 years old, and gross domestic product (GDP) per capita at the city level were collected from the website of $\mathrm{Na}$ tional Bureau of Statistics of China (most recent update in the year of 2017) (www.stats.gov.cn). Additionally, three key medical access related variables including number of hospitals, number of hospital beds, and number of clinical staffs per 1000 people, were also collected from National Bureau of Statistics of China (www.stats. gov.cn). Selenium content measured from crops (including corn, barley, rice, sorghum, millet, potatoes, broad beans, wheat, etc.) at the county level [23] and from topsoil at sampling site level [24], were used for the current analysis. Both data were obtained from the Chinese Academy of Agricultural Sciences.

Then selenium content of crops for each city were calculated by averaging the selenium content at county level. The selenium content in topsoil for each city was defined as the weighted average of area-based selenium content. All cites were classified into 3 categories: non-selenium-deficient areas $(>0.06 \mathrm{ppm}), \quad$ moderate-selenium-deficient areas (0.03-0.06 ppm), and severe-selenium-deficient areas $(<0.03 \mathrm{ppm})$ according to selenium content in crops, and were grouped into non-selenium-deficient areas (concentration $>0.31 \mathrm{mg} / \mathrm{kg}$ ), moderate-seleniumdeficient areas $(0.18-0.31 \mathrm{mg} / \mathrm{kg})$, and severeselenium-deficient areas $(<0.18 \mathrm{mg} / \mathrm{kg})$ according to selenium content in topsoil. 


\section{Geographical analysis of COVID-19 mortality}

Each COVID-19 case was geo-referenced to the corresponding polygons of the China digital map through the linkage of the 4-digit city geo-code. The average CFR that was calculated at city level was overlapped on the selenium concentration of crops and topsoil to create a thematic map by using ArcGIS 10.7 (Environmental Systems Research Institute Inc., Redlands, CA, USA). The COVID-19 related fatality rates were compared across different selenium levels by chi-squared test. The Zeroinflated negative binomial regressions were applied to estimate the relationship between CFR of COVID-19 and selenium deficiency by using "zeroinfl" function in $\mathrm{R}$ package "pscl". The number of COVID-19 deaths per city was set as the outcome variable, and the total case number was included as an "offset term (in logtransformed form)" included in model for each city. The population density, GDP per capita, proportion of population over 60 years old, number of hospitals, number of hospital beds, and number of clinical staffs per 1000 people were included as co-variables. The incidence rate ratio (IRR) in response to the change of each variable by a given amount (e.g.,100 persons per $\mathrm{km}^{2}$ for population density, 10 thousand Yuan per person for GDP per capita, and $1 \%$ for proportion of population over 60 years old) was used to determine its impact on CFR. The 95\% confidence intervals (CIs) and $P$ value were estimated after correcting for over dispersion, due to spatial clustering patterns and zero death in some cities [25]. The univariate analyses were separately performed to examine the effect of each variable, based on which covariables with a $P<0.20$ were further included for the multivariate analysis. A $P$ value of $<0.05$ was considered statistically significant. Statistical analysis was done using $\mathrm{R}$ version 3.6.3.

\section{Results}

Geographical analysis of COVID-19 fatality

From 8 December 2019 to 13 December 2020, a total of 15,434 confirmed COVID-19 cases were reported from 312 cities outside Hubei Province. Totally, 64 cities had reported 120 cases outside Hubei Province, leading to an overall CFR of $0.78 \%(120 / 15,385)$. For the cities with deaths, the median fatality rate was $3.12 \%$ (IQR: 1.38 $6.26 \%$ ). A total of 147 cities each reporting over 20 cases were included in the current analysis. In these cities, $91 \%(14,045)$ of total cases and $85.8 \%$ (103) of total mortality from COVID-19 in China had been reported.

The CFR of COVID-19 on the map of selenium content in crops at the city level (Fig. 1a). Among the studied 147 cities, 75 (51.0\%) and $22(15.0 \%)$ were grouped into moderate and severe selenium deficient areas based on selenium content in crops, respectively. This is largely consistent with the grouping based on the selenium content in topsoil (Spearman correlation coefficient of $0.46, p<0.001)$. Among the top 10 cities with the highest CFRs (3.70-8.51\%), four cities were grouped as severe-selenium-deficient regions and five were moderate-selenium-deficient regions (Table 1, Fig. 1a). Most of the hotspots of highest CFRs of COVID-19 fell within the selenium-deficient belt [26], located in northeastern and central areas of the mainland of China, respectively. Notably, in Heilongjiang Province in northeastern China, significantly higher CFRs ranging from 1.52 to $8.51 \%$ were observed from the cities with the most severe-selenium-deficiency in China [27]. For other provinces, such as in Shandong, Hebei, and Henan provinces, neighboring cities with comparable socioeconomic level, had also displayed CFRs with high variance, which were correlated with the extent of selenium deficiency (Fig. 1a).

The CFR of COVID-19 was further overlapped on the map of selenium content in topsoil (Fig. 1b). In line with results from selenium content in crops, nine among the top 10 cities with the highest CFRs were selenium deficient, including six severe-selenium-deficient regions and three moderate-selenium-deficient regions (Table $1)$.

\section{Correlation analysis between COVID-19 fatality and selenium deficiency}

The overall CFRs of COVID-19 for the analyzed cities were inversely related to the selenium content in crops, which gradually increased from $1.17 \%$ in non-seleniumdeficient areas, to $1.28 \%$ in moderate-selenium-deficient areas, and further to $3.16 \%$ in severe-selenium-deficient areas $(p=0.002$, Table 2$)$. The zero-inflated negative binomial regression model showed a significantly higher risk of mortality conferred from severe-seleniumdeficient cities, with incidence rate ratio (IRR) of 3.88 (95\% CIs: 1.21-12.52), in comparison with nondeficiency $(P=0.023$; Table 2). No statistical difference of CFR due to COVID-19 was shown between moderate-selenium-deficient cities and non-seleniumdeficient cities (IRR: 1.92, 95\% CIs: 1.00-3.69, $P=0.051$ ).

A more robust effect was observed when selenium content in topsoil was used for correlation analysis. The crude CFRs from non-selenium-deficient to severeselenium-deficient areas were $0.76 \%, 1.70 \%$ and $1.85 \%$ respectively $(p<0.001$, Table 2$)$. The result of zeroinflated negative binomial regression model revealed significantly increased CFR that was observed from both moderate-selenium-deficient and severe-seleniumdeficient cities, with the IRR (95\% CIs) estimated to be 2.38 (1.14-4.98) and 3.06 (1.49-6.27), respectively, when using non-selenium-deficient cities as reference. For both models built on different selenium contents, no significant effect on CFR of COVID-19 was observed from 

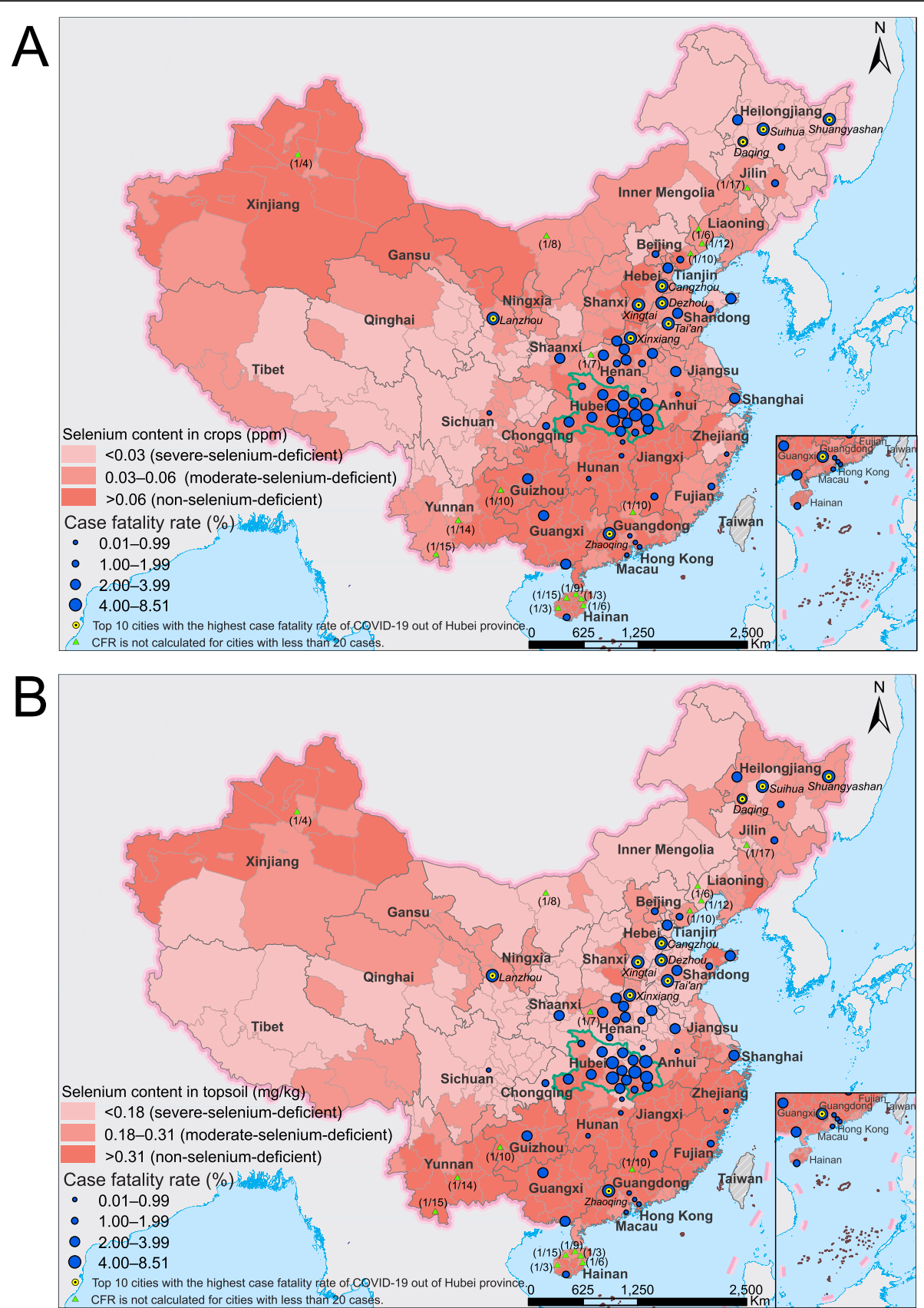

Fig. 1 The case fatality rate of COVID-19 and selenium deficiency at the city level based on selenium content in crops (Panel a) and topsoil (Panel $\mathbf{b}$ ) in the mainland of China. The background color of the map represents the selenium level at the city level. The dots display the average fatality rate of COVID-19 at the city level. The average fatality rate was only shown for cities reporting least one death. The fatality rate of cities with $<20$ deaths are indicated in brackets

other demographic, social or medical access related variables, including population density, GDP per capita, and proportion of population over 60 years old, number of hospitals, number of hospital beds, and number of clinical staffs per 1000 people (data not shown).

\section{Discussion}

In this study, a statistically significant ecological association between CFR of COVID-19 and selenium deficiency, measured from both crops and topsoil, was found in the mainland of China. In comparison with 
Table 1 Top 10 cities with the highest case fatality rates of COVID-19 in China

\begin{tabular}{|c|c|c|c|c|}
\hline City $^{a}$ & No. of cases & Case fatality rate (\%) & Selenium feed level ${ }^{b}$ & Selenium soil level $^{c}$ \\
\hline Suihua & 47 & 8.51 & severe-selenium-deficient & severe-selenium-deficient \\
\hline Cangzhou & 49 & 6.12 & moderate-selenium-deficient & severe-selenium-deficient \\
\hline Shuangyashan & 52 & 5.77 & severe-selenium-deficient & moderate-selenium-deficient \\
\hline Taian & 35 & 5.71 & severe-selenium-deficient & severe-selenium-deficient \\
\hline Lanzhou & 36 & 5.56 & moderate-selenium-deficient & moderate-selenium-deficient \\
\hline Dezhou & 37 & 5.41 & moderate-selenium-deficient & severe-selenium-deficient \\
\hline Xinxiang & 57 & 5.26 & moderate-selenium-deficient & severe-selenium-deficient \\
\hline Zhaoqing & 20 & 5.00 & non-selenium-deficient & non-selenium-deficient \\
\hline Xingtai & 23 & 4.35 & moderate-selenium-deficient & severe-selenium-deficient \\
\hline Daqing & 27 & 3.70 & severe-selenium-deficient & moderate-selenium-deficient \\
\hline
\end{tabular}

${ }^{a}$ We included only 147 cities from which at least 20 cases were reported

${ }^{b}$ Selenium content in crops: Severe-selenium-deficient areas indicate selenium content in crops: $<0.03$ ppm (ppm); Moderate-selenium-deficient areas indicate selenium content in crops: $0.03-0.06 \mathrm{ppm}(\mathrm{ppm})$; non-selenium-deficient indicate selenium content in crops: $>0.06 \mathrm{ppm}$

'Selenium content in topsoil: Deficient areas indicate selenium content in topsoil: $<0.18 \mathrm{mg} / \mathrm{kg}$; Moderate-selenium-deficient areas indicate selenium content in topsoil: $0.18-0.31 \mathrm{mg} / \mathrm{kg}$; non-selenium-deficient indicate selenium content in topsoil: $>0.31 \mathrm{mg} / \mathrm{kg}$

previous study that reported a significant association between cure rate and background selenium status in cities outside Hubei [20], our study had the advantage that most recent updated data were used for analysis. The current data on intake of selenium were obtained based on the most extensive investigation of selenium content in crops that covered all 2922 counties, and 4095 investigation sites of selenium content in topsoil. The highly credible fatality data in China was accessible as the epidemic has been largely brought to an end, with highly sporadic new cases and no new death reported for a long duration, also giving an optimal opportunity to make fatality related analysis. A current clinical study performed in German verified the association between Se and clinical outcomes of COVID-19, where a pronounced deficit in total serum Se was displayed in SARS-COV-2 infected cases, with Se deficiency more severe in the nonsurvivors as compared with survivors of COVID-19 [28].

The potential mechanism how the selenium deficiency can lead to a more severe infection is complex. Most of biological functions of selenium are exerted through its incorporation as a rare amino acid selenocysteine in the essential family of selenoproteins [5, 29]. At least 25 selenoproteins have been identified in humans [29], most of which are involved in a redox reaction [8]. Glutathione peroxidases, the major components of the human antioxidant defense, play a critical role in redox signaling and other immune responses in acute stress conditions $[8,12]$. This has been evidenced by an obvious correlation between low selenium and worse clinical

Table 2 Association between case fatality rate of COVID-19 and the selenium level in China

\begin{tabular}{|c|c|c|c|c|}
\hline \multirow[t]{2}{*}{ City selenium level $^{a}$} & \multirow{2}{*}{$\begin{array}{l}\text { Crude } \\
\text { CFR } \\
(\%)^{b}\end{array}$} & \multirow{2}{*}{$\begin{array}{l}P \\
\text { value }^{b}\end{array}$} & \multicolumn{2}{|c|}{ Zero-inflated negative binomial regression $^{d}$} \\
\hline & & & $\overline{\text { IRR }(95 \% \mathrm{Cls})^{c}}$ & $P$ value \\
\hline \multicolumn{5}{|l|}{ Selenium content in crops (ppm) } \\
\hline$>0.06$ (non-selenium-deficient areas) & 1.17 & 0.002 & 1 & - \\
\hline 0.03-0.06 (moderate-selenium-deficient areas) & 1.28 & & $1.92(1.00-3.69)$ & 0.051 \\
\hline$<0.03$ (severe-selenium-deficient areas) & 3.16 & & $3.88(1.21-12.52)$ & 0.023 \\
\hline \multicolumn{5}{|l|}{ Selenium content in topsoil (mg/kg) } \\
\hline$>0.31$ (non-selenium-deficient areas) & 0.76 & $<0.001$ & 1 & - \\
\hline $0.18-0.31$ (moderate-selenium-deficient areas) & 1.70 & & $2.38(1.14-4.98)$ & 0.021 \\
\hline$<0.18$ (severe-selenium-deficient areas) & 1.85 & & $3.06(1.49-6.27)$ & 0.002 \\
\hline
\end{tabular}

We included only 147 cities from which at least 20 cases were reported

${ }^{b}$ The crude case fatality rates (CFRs) were calculated by dividing the number of deaths by the number of cases within the region. The $P$ values were calculated by chi-square tests

IRR (95\% Cls): incidence rate ratio with $95 \%$ confidence intervals

${ }^{d}$ The Zero-inflated negative binomial regression were used for evaluating the association between the selenium level and case fatality rate at the city level. Only IRR $(95 \% \mathrm{Cls})$ of count model (negative binomial with "log" link) was shown in the table, and the multivariate analysis had the same results with the univariate analysis due to non-significant effects of demographic, social and medical access related covariates, including population density, GDP per capita, proportion of population over 60 years old, number of hospitals, number of hospital beds, and number of clinical staffs per 1000 people on the case fatality rate for COVID-19 
outcomes in critically ill patients [30]. Interestingly a recent metabolomic profiling of SARS-COV-2 infected VeroFM cells had revealed the most pronounced upregulation of glutathione and pyrimidine metabolism, which were responsible for elimination of reactive oxygen species [31], implying the induction of antioxidant defense against SARS-COV-2 infection, and thus indicating a potential role of biological activities of selenium during this process. Besides, like other RNA viruses including HIV and Ebola virus, SARS coronaviruses could probably use host cellular selenium to complete the expression of the viral selenopeoteins $[32,33]$, thus, a selenium deficient status in the infected host might be induced during the acute phase of illness when the virus intensely replicated. A recent review suggested that redox-active selenium species formed at high selenium intake might hypothetically inhibit SARS-CoV-2 proteases. Thus, by interfering with the human selenoprotein system, SARS-CoV-2 could evade an adequate host response [34].

On the other hand, selenium might affect the blood coagulation and thrombosis formation in the form of sodium selenite that could decrease thromboxane A2 (TXA2) formation that plays a key role in blood platelet activation and aggregation [35, 36]. It is well documented from a number of hemorrhagic fever viruses, including Hantavirus and Ebola virus that selenium might be involved in the hemorrhagic manifestations by affecting the prostacyclin/TXA2 ratio and thus blood clotting [37]. This mechanism could support the association between selenium deficiency and more coagulation dysfunction in COVID-19, i.e., thrombocytopenia, prolonged APTT and PT, as well as increased DIC development, according to the current findings. All these indicators are critical factors in determining the disease severity in COVID-19 [38], thus providing potential mechanism how selenium could be involved in this process. A most recent study, based on a linear association between selenium deficiency with hypoglycemia in healthy adults, also supported the role of adequate Se supply for glucose homeostasis in human subjects [39]. This newly identified relationship may be of relevance for the course of severe complications in COVID-19 with mortality risk. Recognition of these mechanisms by which selenium might potentially benefit COVID-19 patients provides a rationale for selenium supplementation in SARS-CoV-2 infection. Existing data on the effect from daily selenium supplementation to treat viral infection, most notably with respect to HIV and influenza A virus infections, are heterogeneous [16]. In one clinical study, although selenium supplementation delayed CD4 decline in HIV-infected patients, no evidence of suppressing or reducing HIV viral load was seen [40]. Inconsistent results of benefits with routine multiple micronutrient supplementation in HIV infection was noticed from numerous clinical trials [41]. However, these findings should not be interpreted as a reason to deny micronutrient supplements for people with known specific deficiencies or with lower diet level under the recommended allowance. Particularly for the eldly, who had high odds of progressing into fatal COVID and were more likely to be with selenium deficiency, might gain some benefit from prophylactic micronutrition supplementation.

The study was subject to several limitations. First, selenium status in the population could not be fully represented by the selenium concentration measured from local crops or topsoil, since the supplies of food were not restricted to local sources and dietary habits also played key role in effective selenium intake [42]. Besides, the effect of selenium deficiency might be confounded by several other insufficient dietary nutrients such as vitamins, $\mathrm{Ca}, \mathrm{Fe}, \mathrm{Zn}$ and I [43], and the migration bias related with transport of crops or routes of foods might also exist [44]. However, considering that almost all provinces in China except for Beijing and Shanghai had been self-sufficient in grain and vegetables according to the production and consumption data of grain and vegetables of them from China Statistical Yearbook 2020 of National Bureau of Statistics (http://www.stats.gov.cn), it's reasonable to assume that local food and drinking water are the major source of selenium intake, thus causing minor bias in eliciting the association. Additionally, given the persistent travel restriction during the intense COVID-19 epidemic, the migration bias due to transport of crops or routes of foods could be minimized. Second, the nationwide data on selenium concentration in crops or topsoil are old. As we known, the nationwide selenium data are not updated in recent decades due to the large amount of work for conducting a nationwide survey of selenium concentration in crops or topsoil. Besides, bioavailability of selenium in soil (such as $\mathrm{pH}$, humic matter content), which could affect the process of selenium in topsoil entering the food chain [45], was not taken into account in the analysis. At last, our data of selenium concentration in crops or topsoil were categorical variable which limited us for further assessing the potential threshold or nonlinear relation effects. Given the toxic effect of excess selenium, it should be cautious about extrapolation of current results. Despite of current findings, the role of selenium in COVID-19 needs to be replicated in other selenium deficient countries and further validated at individual-level. However, when the results of ecological research are applied to the individual level, ecological fallacies should be alerted. Thus, even though previous evidences and the current study supported the risk of selenium deficiency [46, 47], additional experimental studies are warranted to 
explore possible mechanisms of selenium deficiency in causing death risk of COVID-19. Before selenium supplementation could be recommended for patients with SARS-CoV-2 infection in severe seleniumdeficient areas, the necessary caution of avoiding selenium toxicity should be raised [48].

\section{Abbreviation}

CFR: Case fatality rate

\section{Acknowledgements}

We appreciate Professor Ai-Guo Xu for providing us the data of selenium content of topsoil in the ecological analysis between COVID-19 mortality and selenium deficiency, which is from State Key Research Project "China Digital Soil Maps (CDSM) at 1:50000 Scale\&Digital Soil with High Resolution (2006FY120200, 2012FY112100)", Institute of Agricultural Resources and Agricultural Regional Planning, Chinese Academy of Agricultural Sciences. 2017.

\section{Authors' contributions}

LQF and WL conceived and designed the study. HYZ and ARZ contributed to data collection. HL, QBL, LQF, HYZ, ARZ, XAZ, ZJZ, XGG, TLC and YY contributed to data analysis. LQF, LW, and $H L$ contributed to the writing of the report. HYZ and ARZ contributed equally and share first authorship. The author(s) read and approved the final manuscript.

\section{Funding}

This work supported by the China Mega-Project on Infectious Disease Prevention (2018ZX10713002, 2018ZX10201001, 2018ZX10101003, 2018ZX10301401), the National Natural Science Foundation of China (81825019), and The Key Research and Development Program of China (2019YFC1200604)

\section{Availability of data and materials}

The dataset analyzed during the current study is available from the corresponding author on reasonable request.

\section{Declarations}

Ethics approval and consent to participate

The current study was approved by the ethics committees of Beijing Institute of Microbiology and Epidemiology in accordance with the medical research regulations of China.

\section{Consent for publication}

Not applicable.

\section{Competing interests}

All authors declare no competing interests.

\section{Author details \\ ${ }^{1}$ State Key Laboratory of Pathogen and Biosecurity, Beijing Institute of Microbiology and Epidemiology, 20 Dong-Da Street, Fengtai District, Beijing 100071, People's Republic of China. ${ }^{2}$ School of Public Health, Cheeloo College of Medicine, Shandong University, 44 West Wenhua Road, Jinan, Shandong 250012, People's Republic of China. ${ }^{3}$ College of Public Health and Health Professions, Emerging Pathogens Institute, University of Florida, Gainesville, Florida 32610, USA. ${ }^{4}$ School of Public Health, Peking University, Beijing 430071, People's Republic of China. ${ }^{5}$ Department of Epidemiology and Health Statistics, School of Public Health, Fudan University, Shanghai, People's Republic of China.}

Received: 1 March 2021 Accepted: 10 May 2021

Published online: 19 May 2021

\section{References}

1. World Health Organization. Coronavirus disease (COVID-19) pandemic. https://www.who.int/emergencies/diseases/novel-coronavirus-2019. Accessed 23 Dec 2020.
2. Beigel JH, Tomashek KM, Dodd LE, Mehta AK, Zingman BS, Kalil AC, et al. Remdesivir for the treatment of Covid-19 - final report. N Engl J Med. 2020; 383(19):1813-26. https://doi.org/10.1056/NEJMoa2007764.

3. Gombart AF, Pierre A, Maggini S. A review of micronutrients and the immune system-working in harmony to reduce the risk of infection. Nutrients. 2020;12(1):236.

4. Calder PC, Carr AC, Gombart AF, Eggersdorfer M. Optimal nutritional status for a well-functioning immune system is an important factor to protect against viral infections. Nutrients. 2020;12(4):1181.

5. Fairweather-Tait SJ, Bao Y, Broadley MR, Collings R, Ford D, Hesketh JE, et al. Selenium in human health and disease. Antioxid Redox Signal. 2011;14(7): 1337-83. https://doi.org/10.1089/ars.2010.3275.

6. Guillin OM, Vindry C, OhImann T, Chavatte L. Selenium, Selenoproteins and viral infection. Nutrients. 2019;11(9):2101.

7. Harthill M. Review: micronutrient selenium deficiency influences evolution of some viral infectious diseases. Biol Trace Elem Res. 2011;143(3):1325-36. https://doi.org/10.1007/s12011-011-8977-1.

8. Touat-Hamici Z, Legrain Y, Bulteau AL, Chavatte L. Selective up-regulation of human selenoproteins in response to oxidative stress. J Biol Chem. 2014; 289(21):14750-61. https://doi.org/10.1074/jbc.M114.551994.

9. Beck MA, Levander OA, Handy J. Selenium deficiency and viral infection. J Nutr. 2003;133(5 Suppl 1):1463s-7s.

10. Loscalzo J. Keshan disease, selenium deficiency, and the selenoproteome. N Engl J Med. 2014;370(18):1756-60. https://doi.org/10.1056/NEJMcibr1402199.

11. Avery JC, Hoffmann PR. Selenium, Selenoproteins, and Immunity. Nutrients. 2018;10(9):1203

12. Beck MA, Levander OA. Dietary oxidative stress and the potentiation of viral infection. Annu Rev Nutr. 1998;18(1):93-116. https://doi.org/10.1146/a nnurev.nutr.18.1.93.

13. Beck MA, Shi Q, Morris VC, Levander OA. Rapid genomic evolution of a nonvirulent coxsackievirus B3 in selenium-deficient mice results in selection of identical virulent isolates. Nat Med. 1995;1(5):433-6. https://doi.org/10.1038/ nm0595-433.

14. Fawzi W. Micronutrients and human immunodeficiency virus type 1 disease progression among adults and children. Clin Infect Dis. 2003;37(Suppl 2): S112-6. https://doi.org/10.1086/375882.

15. Rayman MP. Selenium and human health. Lancet. 2012;379(9822):1256-68.

16. Steinbrenner H, Al-Quraishy S, Dkhil MA, Wunderlich F, Sies H. Dietary selenium in adjuvant therapy of viral and bacterial infections. Adv Nutr. 2015;6(1):73-82.

17. Rees K, Hartley L, Day C, Flowers N, Clarke A, Stranges S. Selenium supplementation for the primary prevention of cardiovascular disease. Cochrane Database Syst Rev. 2013;2013(1):Cd009671.

18. Vinceti M, Filippini T, Del Giovane C, Dennert G, Zwahlen M, Brinkman M, et al. Selenium for preventing cancer. Cochrane Database Syst Rev. 2018; 1(1):Cd005195

19. Cheng C, Chen SY, Geng J, Zhu PY, Liang RN, Yuan MZ, et al. Preliminary analysis on COVID-19 case spectrum and spread intensity in different provinces in China except Hubei province. Zhonghua liu xing bing xue za zhi $=$. Zhonghua liuxingbingxue zazhi. 2020;41(10):1601-5. https://doi.org/1 0.3760/cma.j.cn112338-20200314-00347.

20. Zhang J, Taylor EW, Bennett K, Saad R, Rayman MP. Association between regional selenium status and reported outcome of COVID-19 cases in China. Am J Clin Nutr. 2020;111(6):1297-9. https://doi.org/10.1093/ajcn/nqaa095.

21. DXY. Novel coronavirus global real-time outbreak map. https://ncov.dxy.cn/ ncovh5/view/pneumonia?from $=d x y \&$ source $=\&$ link $=\&$ share $=$. Accessed 23 Dec 2020.

22. The Novel Coronavirus Pneumonia Emergency Response Epidemiology Team. The epidemiological characteristics of an outbreak of 2019 novel coronavirus diseases (COVID-19) - China, 2020. China CDC Weekly. 2020;2(8):113-22.

23. Shu Q, Wang G, Duan Y, Lu Z, Liu J. A distribution map of selenium content of crops in mainland China. Beijing: China Agricultural Science and Technology Press; 1985.

24. Zhang WL, Zhang RL, Xu AG, Tian YG, Yao Z, Duan ZY. Development of China digital soil maps (CDSM) at 1: 50000 scale. Sci Agric Sin. 2014;47: 3195-213 (in Chinese)

25. Lee HW, Lee PW, Johnson KM. Isolation of the etiologic agent of Korean hemorrhagic fever. J Infect Dis. 1978;137(3):298-308. https://doi.org/10.1093/ infdis/137.3.298

26. Yang C, Yao H, Wu Y, Sun G, Yang W, Li Z, et al. Status and risks of selenium deficiency in a traditional selenium-deficient area in Northeast China. Sci Total Environ. 2021;762:144103. https://doi.org/10.1016/j.scitotenv.2020.144103. 
27. Sun GX, Meharg AA, Li G, Chen Z, Yang L, Chen SC, et al. Distribution of soil selenium in China is potentially controlled by deposition and volatilization? Sci Rep. 2016;6(1):20953. https://doi.org/10.1038/srep20953.

28. Moghaddam A, Heller RA, Sun Q, Seelig J, Cherkezov A, Seibert L, et al. Selenium Deficiency Is Associated with Mortality Risk from COVID-19. Nutrients. 2020;12(7):2098.

29. Papp LV, Lu J, Holmgren A, Khanna KK. From selenium to selenoproteins: synthesis, identity, and their role in human health. Antioxid Redox Signal. 2007;9(7):775-806. https://doi.org/10.1089/ars.2007.1528.

30. Manzanares W, Biestro A, Galusso F, Torre MH, Mañay N, Pittini G, et al. Serum selenium and glutathione peroxidase-3 activity: biomarkers of systemic inflammation in the critically ill? Intensive Care Med. 2009:35(5): 882-9. https://doi.org/10.1007/s00134-008-1356-5.

31. Gassen NC, Papies J, Bajaj T, Dethloff F, Emanuel J, Weckmann K, et al. Analysis of SARS-CoV-2-controlled autophagy reveals spermidine, MK-2206, and niclosamide as putative antiviral therapeutics. bioRxiv. 2020. https://doi. org/10.1101/2020.04.15.997254.

32. Taylor EW, Zhao L, Zhang J. Genomic analysis of SARS coronavirus reveals two hidden genes whose predicted functions suggest a molecular basis for selenium-related abnormalities in SARS. In: ABSTRACT for invited oral presentation. Beijing: International Science Symposium on SARS; 2003. https://doi.org/10.6084/m9.figshare.12133581.

33. Taylor EW, Ruzicka JA, Premadasa L, Zhao L. Cellular Selenoprotein mRNA tethering via antisense interactions with Ebola and HIV-1 mRNAs may impact host selenium biochemistry. Curr Top Med Chem. 2016;16(13):15305. https://doi.org/10.2174/1568026615666150915121633.

34. Zhang J, Saad R, Taylor EW, Rayman MP. Selenium and selenoproteins in viral infection with potential relevance to COVID-19. Redox Biol. 2020;37: 101715. https://doi.org/10.1016/j.redox.2020.101715.

35. Perona G, Schiavon R, Guidi GC, Veneri D, Minuz P. Selenium dependent glutathione peroxidase: a physiological regulatory system for platelet function. Thromb Haemost. 1990;64(2):312-8.

36. Ersöz G, Yakaryilmaz A, Turan B. Effect of sodium selenite treatment on platelet aggregation of streptozotocin-induced diabetic rats. Thromb Res. 2003;111(6):363-7. https://doi.org/10.1016/S0049-3848(03)00338-4.

37. Ramanathan CS, Taylor EW. Computational genomic analysis of hemorrhagic fever viruses. Viral selenoproteins as a potential factor in pathogenesis. Biol Trace Elem Res. 1997;56(1):93-106. https://doi.org/10.1007/BF02778985.

38. Tang N, Li D, Wang X, Sun Z. Abnormal coagulation parameters are associated with poor prognosis in patients with novel coronavirus pneumonia. J Thrombosis Haemostasis. 2020;18(4):844-7. https://doi.org/1 $0.1111 /$ jth. 14768

39. Wang Y, Rijntjes E, Wu Q, Lv H, Gao C, Shi B, et al. Selenium deficiency is linearly associated with hypoglycemia in healthy adults. Redox Biol. 2020;37: 101709. https://doi.org/10.1016/j.redox.2020.101709.

40. Muzembo BA, Ngatu NR, Januka K, Huang HL, Nattadech C, Suzuki T, et al. Selenium supplementation in HIV-infected individuals: a systematic review of randomized controlled trials. Clin Nutr ESPEN. 2019;34:1-7. https://doi. org/10.1016/j.clnesp.2019.09.005.

41. Visser ME, Durao S, Sinclair D, Irlam JH, Siegfried N. Micronutrient supplementation in adults with HIV infection. Cochrane Database Syst Rev. 2017;5(5):Cd003650.

42. Filippini T, Michalke B, Wise LA, Malagoli C, Malavolti M, Vescovi L, et al. Diet composition and serum levels of selenium species: a cross-sectional study. Food Chem Toxicol. 2018;115:482-90. https://doi.org/10.1016/j.fct.2018.03.048.

43. Ning Y, Wang X, Zhang P, Anatoly SV, Prakash NT, Li C, et al. Imbalance of dietary nutrients and the associated differentially expressed genes and pathways may play important roles in juvenile Kashin-Beck disease. J Trace Elements Med Biol. 2018;50:441-60. https://doi.org/10.1016/j.temb.2018.01.012.

44. Tong S. Migration bias in ecologic studies. Eur J Epidemiol. 2000;16(4):365-9. https://doi.org/10.1023/A:1007698700119.

45. Johnson CC, Fordyce FM, Rayman MP. Symposium on 'Geographical and geological influences on nutrition': factors controlling the distribution of selenium in the environment and their impact on health and nutrition. Proc Nutr Soc. 2010;69(1):119-32. https://doi.org/10.1017/S0029665109991807.

46. Diez-Roux AV. Bringing context back into epidemiology: variables and fallacies in multilevel analysis. Am J Public Health. 1998;88(2):216-22. https:// doi.org/10.2105/AJPH.88.2.216.

47. Idrovo AJ. Three criteria for ecological fallacy. Environ Health Perspect. 2011; 119(8):A332. https://doi.org/10.1289/ehp.1103768.
48. Vinceti M, Filippini T, Rothman KJ. Selenium exposure and the risk of type 2 diabetes: a systematic review and meta-analysis. Eur J Epidemiol. 2018;33(9): 789-810. https://doi.org/10.1007/s10654-018-0422-8.

\section{Publisher's Note}

Springer Nature remains neutral with regard to jurisdictional claims in published maps and institutional affiliations.
Ready to submit your research? Choose BMC and benefit from:

- fast, convenient online submission

- thorough peer review by experienced researchers in your field

- rapid publication on acceptance

- support for research data, including large and complex data types

- gold Open Access which fosters wider collaboration and increased citations

- maximum visibility for your research: over $100 \mathrm{M}$ website views per year

At BMC, research is always in progress.

Learn more biomedcentral.com/submissions 